\title{
Lignin recovery and it effects quality of anaerobic treated palm oil mill effluent (AT- POME)
}

\author{
Abdul Haqi Ibrahim ${ }^{1,2}$, Muhammad Fahmi Ridwan ${ }^{1,2}$, Che Zulzikrami Azner Abidin ${ }^{1,2}$, \\ Soon Ann Ong ${ }^{1,2}$, Yee Shian Wong ${ }^{1,2}$, Ayu Wazira Azhari ${ }^{1}$, and Siti Norruhaidawati Ozir ${ }^{2}$ \\ ${ }^{1}$ WAREG, School of Environmental Engineering, Universiti Malaysia Perlis (UniMAP), 01000, \\ Perlis, Malaysia. \\ ${ }^{2}$ School of Environmental Engineering, Universiti Malaysia Perlis (UniMAP), 01000, Perlis, \\ Malaysia.
}

\begin{abstract}
Lignin is one of the main structural polymers present in plant tissue. It can also be found as an isolated product of the pulp and paper industry. Palm oil mill effluent (POME) has been known as high strength industrial wastewater that is difficult to treat due to its large variety of inorganic and organic contents. The main purpose of this study is to recover soluble lignin from anaerobically treated palm oil mill effluent (AT-POME) and indirectly improves the quality of AT-POME. AT-POME was adjusted to different $\mathrm{pH}$ using different type of acids. Response Surface Methodology (RSM) was utilized to obtain the optimum operating parameters as well as to analyse the interaction between them. Model shows that $74.67 \%$ of lignin can be recovered from AT-POME after 5 minutes reaction time using sulfuric acid $\left(\mathrm{H}_{2} \mathrm{SO}_{4}\right)$ at $\mathrm{pH}$ 5. Hence from the experiment, it was proved that simple $\mathrm{pH}$ adjustment could precipitate the soluble lignin from AT-POME.
\end{abstract}

\section{Introduction}

Lignin is one of the important compounds of the cell wall plant. Lignin is nature's most aromatic polymer, and the second renewable natural resource (after cellulose) and it is traditionally viewed as waste material or low value by product.

The application of lignin is depending on the possibilities of either degrading it into low molecular weight aromatics or to take advantage of lignin as a multi-functional macromolecule [1]. Because of its polyaromatic nature and great availability, lignin has big potential to serve as future "green" source for aromatic chemicals, especially phenols [2].

In addition, various possible value-added applications for lignin without conversion such as blending with polyolefins giving UV stabilization [3-4] or blending with PL giving $100 \%$ renewable resins [5] or take advantage of its antimicrobial and antioxidant action [6$8]$.

*Corresponding author: abdulhaqi@,unimap.edu.my 
Palm oil mill effluent (POME) is one of the major pollutants in Malaysia. This is due to mass production of palm oil in the country. Malaysia is rank as world's second largest producer of palm oil. It is estimated that about 60 million tonnes of POME was produced yearly by the palm oil industries in Malaysia. Anaerobic digestion is widely employed biotechnologies for POME because it is capable to digests the high organic contents of present in POME.

However, lignin (part in lignocellulosic material) is very difficult to biodegrade in an anaerobic environment. As it is hardly/non-biodegradable, soluble lignin imparts black colour (aesthetically inconvenient) and produce bad odour to anaerobically treated POME (AT-POME). Hence, precipitation and recovery of soluble lignin from AT-POME could treat the solution faster. In addition, the recovered lignin can be modified for other uses/purposes.

\section{Methodology}

\subsection{Materials and chemicals}

Samples of AT-POME were collected from Malpom Sdn. Bhd., Nibong Tebal, Penang. Sulfuric acid $\left(\mathrm{H}_{2} \mathrm{SO}_{4}\right)$ and hydrochloric acid $(\mathrm{HCl})$ from $\mathrm{R} \& \mathrm{M}$ Chemicals were used to precipitate lignin from AT-POME. Lignin content in AT-POME was determined by the Tyrosine Method using Tannin-Lignin reagent set produced by $\mathrm{HACH}$.

\subsection{Lignin removal and recovery}

Raw AT-POME was centrifuged at $4000 \mathrm{rpm}$ for 10 minutes to separate any coarse particles present in AT-POME sample. Centrifuged sample was tested for its initial COD and lignin content. Next, $350 \mathrm{ml}$ of AT-POME was poured into conical flask and the $\mathrm{pH}$ was adjusted accordingly. Samples were shaken using mechanical shaken for duration 5, 10 and 15 minutes. After the shaking process, AT-POME was centrifuged once more to separate the precipitated lignin and the supernatant. The precipitated lignin was collected and washed then dried at $105^{\circ} \mathrm{C}$ until constant weight. The supernatants were also tested for its remaining COD and lignin content.

\subsection{Experimental design}

Experimental design and statistical analysis were performed using Design Expert software (version 7.1). The Box-Behnken Design (BBD) and Response Surface Methods (RSM) were used to set up the experimental protocols and optimize the independent process variables for lignin precipitation. The variables and their levels are summarized in Table 1. The chemical oxygen demand (COD) and lignin recovery efficiency was selected as the dependent response variable for this process.

Table 1. Experimental setup for Box-Behnken Design.

\begin{tabular}{|c|c|c|c|}
\hline Factor & Variable & \multicolumn{2}{|c|}{ Range } \\
\hline & & +1 & -1 \\
\hline A & $\mathrm{pH}$ & 5 & 2 \\
\hline B & Reaction time (min) & 5 & 15 \\
\hline $\mathrm{C}$ & Acid Type & $\mathrm{H}_{2} \mathrm{SO}_{4}$ & $\mathrm{HCl}$ \\
\hline
\end{tabular}




\section{Results and discussions}

\subsection{Lignin recovery}

Raw and centrifuged AT-POME contains $1900 \mathrm{mg} / \mathrm{l}$ of COD and $220 \mathrm{mg} / \mathrm{l}$ soluble lignin. Fig. 1 shows the result of the lignin recovery by acid precipitation. The results were varying between all experiments. Highest lignin removal was recorded in Experiment 1 (79.94\%) by using acid $\mathrm{H}_{2} \mathrm{SO}_{4}$ and was adjust using $\mathrm{pH} 3.50$ at 2.93 minutes. While lowest lignin removal was in Experiment 8 that using $\mathrm{pH} 1.38$ for 10.00 minutes.

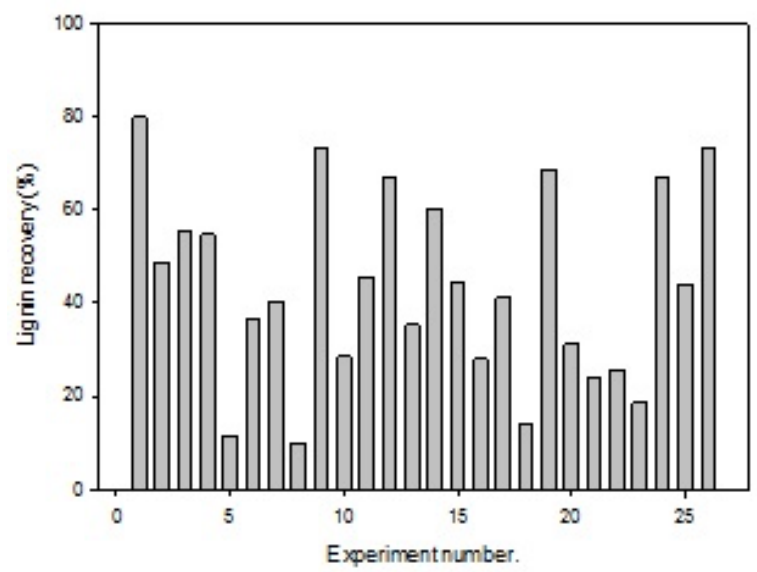

Fig. 1. Lignin recovery from AT-POME.

\subsection{ANOVA analysis of experiment results}

The analysis of variance (ANOVA) of lignin recovery process is shown in Table 2. It suggests that quadratic model was the significant model for precipitation of lignin from AT-POME by acids since the F-value was 1.59 . F-value for two factors and cubic was the smallest which 1.51 and 0.36 . Hence, quadratic model still the most significant model for this experiment. The suggested equation by the RSM as in Equation 1 where A is $\mathrm{pH}, \mathrm{B}$ is reaction time and $\mathrm{C}$ is acid type.

$$
\begin{gathered}
\text { Lignin recovery }(\%)=+45.08+10.13 A-3.57 B-5.50 C-15.06 A B+ \\
2.72 A C+1.49 B C-7.33 A^{2}+3.89 B^{2}
\end{gathered}
$$

Table 2. Statically analysis data for lignin recovery from AT-POME.

\begin{tabular}{|c|c|c|c|c|}
\hline Model & $\begin{array}{c}\text { Sum of } \\
\text { Square }\end{array}$ & $\begin{array}{c}\text { Degree of } \\
\text { Freedom }\end{array}$ & Mean Square & F-Value \\
\hline $\begin{array}{c}\text { Two-Factor } \\
\text { interaction }\end{array}$ & 1623.52 & 3 & 541.17 & 1.51 \\
\hline Quadratic & 1076.01 & 2 & 538.01 & 1.59 \\
\hline Cubic & 745.7 & 5 & 149.14 & 0.36 \\
\hline Linear & 2038.78 & 3 & 679.59 & 1.77 \\
\hline
\end{tabular}




\subsection{Adequacy of fitting model}

The "Model F-value" of 1.75 implies the model is not important to noise. There is a 15.77 $\%$ chance that a "Model F-value" this large could occur due to noise. Values of "Prob > F" less than 0.0500 indicate model terms are significant. In this case A, AB are significant model terms. Values greater than 0.1000 indicate the model terms are not important. The "Lack of Fit F-value" of 1.21 implies the Lack of Fit is not significant relative to the pure error. There is a $38.70 \%$ chance that a "Lack of Fit F-value" this large could occur due to noise.

Table 3. Analysis of Variance (ANOVA) for the quadratic model.

\begin{tabular}{|c|c|c|c|c|c|c|}
\hline \multirow{3}{*}{ Response } & Source & $\begin{array}{c}\text { Sum of } \\
\text { square }\end{array}$ & $\begin{array}{c}\text { Degree of } \\
\text { freedom }\end{array}$ & $\begin{array}{c}\text { Mean } \\
\text { square }\end{array}$ & $\begin{array}{c}\text { F- } \\
\text { value }\end{array}$ & $\begin{array}{c}\text { P-value } \\
\text { (Prob>F }\end{array}$ \\
\hline \multirow{4}{*}{$\begin{array}{c}\text { Lignin } \\
\text { Removal } \\
(\%)\end{array}$} & Model & 4738.32 & 8 & 592.29 & 1.75 & 0.1577 \\
\cline { 2 - 7 } & Residual & 5748.87 & 17 & 338.17 & - & - \\
\cline { 2 - 7 } & Lack of Fit & 2983.01 & 8 & 372.88 & 1.21 & 0.387 \\
\cline { 2 - 7 } & Pure Error & 2765.86 & 9 & 307.32 & - & - \\
\cline { 2 - 7 } & Total & 10487.19 & 25 & - & - & - \\
\cline { 2 - 7 } & $\mathrm{R}^{2}=$ & 0.4518 & & & & \\
\hline
\end{tabular}

Fig. 2 shows the graph for normal plot of residual, which is almost in straight line which supporting the condition that the error terms are normally distributed. While in Fig. 3 , it shows the plot of residual versus predicted values. There is no definite increase of residual with predicted level as all plots are in the range (between -3.00 and +3.00 ). Actual and predicted results are plotted and shown in Fig. 4. Results show that the model is not fit very well as some points are away from the fitted line.

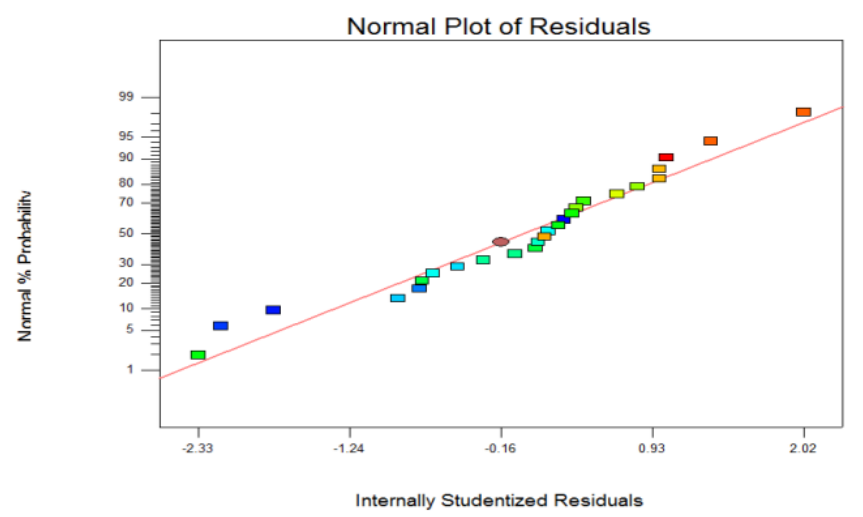

Fig. 2. Normal plot of residue. 


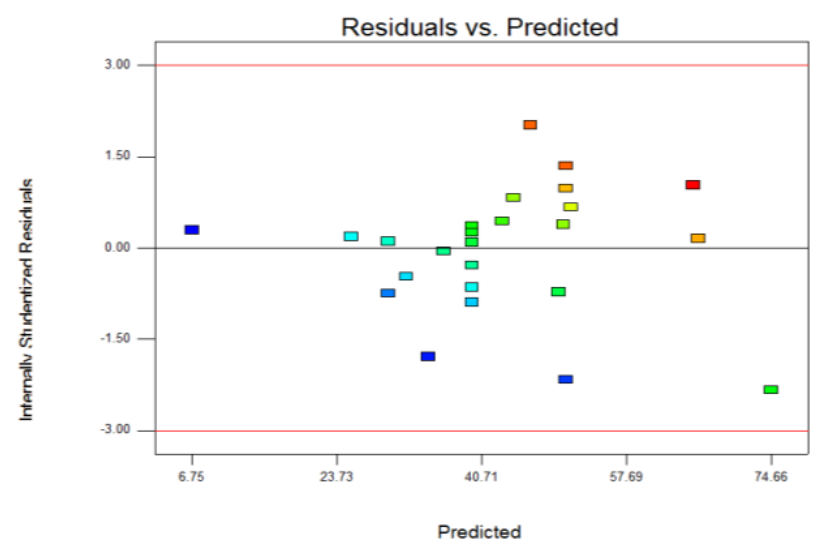

Fig. 3. Residual versus predicted value for percentage of lignin removal.

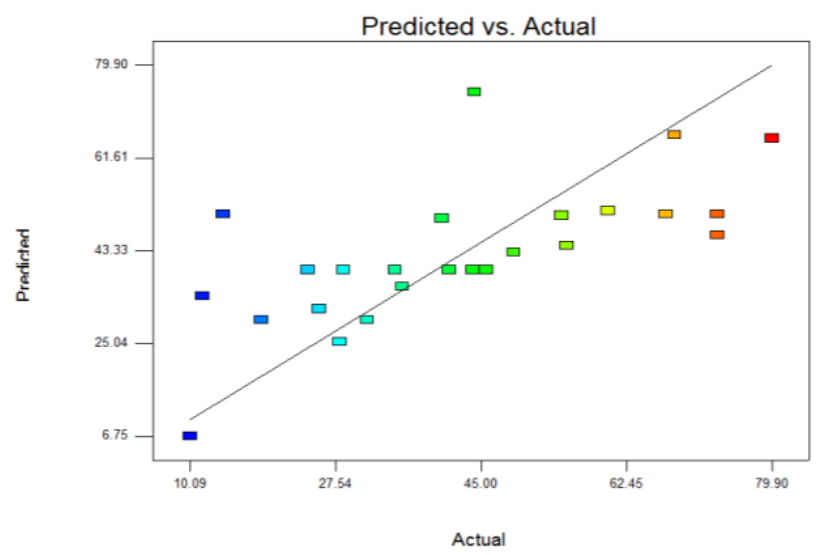

Fig. 4. Predicted versus actual values for percentage of lignin removal.

\subsection{RSM for lignin removal}

Lignin recovery from AT-POME was very much dependent on $\mathrm{pH}$ and reaction time. Fig. 5 and Fig. 6 show the effect of both parameters on lignin recovery from AT-POME using $\mathrm{HCl}$ and $\mathrm{H}_{2} \mathrm{SO}_{4}$ respectively. It was found that the lowest lignin recovery was $10 \%$ at $\mathrm{pH} 2$ with the reaction time of 5 minutes using $\mathrm{HCl}$. The recovery was improved to almost $69 \%$ after the $\mathrm{pH}$ was increased to $\mathrm{pH}$ 5. However, lignin recovery from AT-POME can be further improved when $\mathrm{H}_{2} \mathrm{SO}_{4}$ is used to adjust the $\mathrm{pH}$. When $\mathrm{H}_{2} \mathrm{SO}_{4}$ was used, the lowest and highest recovery approximately $27 \%$ and $75 \%$ respectively. In addition, the effect of reaction time on lignin recovery becomes less when $\mathrm{H}_{2} \mathrm{SO}_{4}$ is used to adjust the $\mathrm{pH}$ as shown in Fig. 6. 


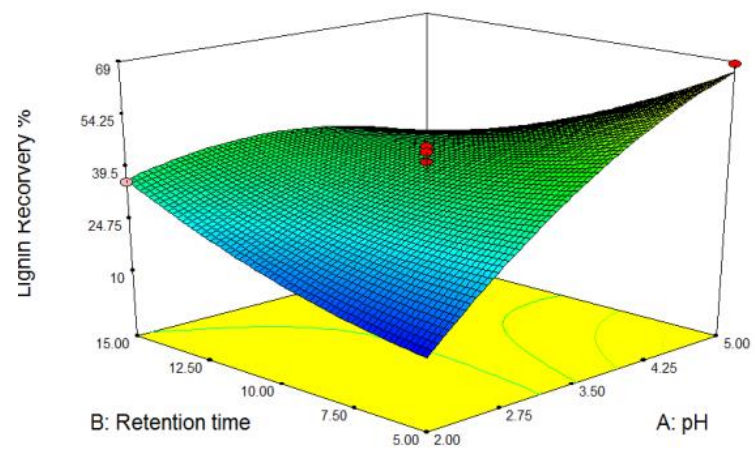

Fig. 5. Three-dimensional surface graph describing the effect of $\mathrm{pH}$ and reaction time on lignin removal (\%); $\mathrm{HCl}$.

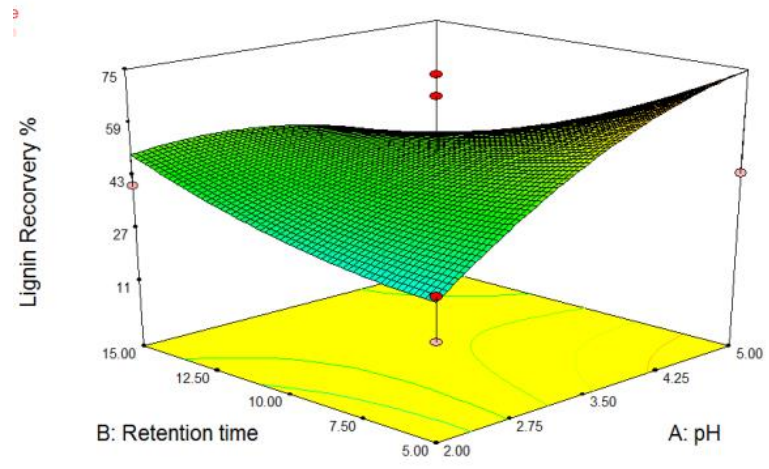

Fig. 6. Three-dimensional surface graph describing effect of $\mathrm{pH}$ and reaction time on lignin removal $(\%) ; \mathrm{H}_{2} \mathrm{SO}_{4}$.

\section{Conclusions}

Acid precipitation is a feasible and simple method to recover lignin from AT-POME. Result shows that sulfuric acid works better compared to hydrochloric acid and $\mathrm{pH}$ of sample solution has been identified as main factor that contribute to the success of lignin recovery from AT-POME.

Authors would like to thank the Ministry of Higher Education for funding this research under the Fundamental Research Grant Scheme (FRGS 9003-00477).

\section{References}

1. D. Stewart, Ind Crops Products 27, 202-207 (2008).

2. C. Amem-Chen, H. Pakdel, C. Roy, Bioresource Technol 79, 277-299 (2001).

3. E. Scott, H.J. De Beukelar. Patent EP0980888, (1999).

4. B. Kosikova, V. Demianova, M. Kacurakova. J Applied Polymer Science 47, 1065 1073 (1993).

5. Q.X. Hou, X.S. Chai, R. Yang, T. Elder, A.J. Ragauska, J Applied Polymer Science 99, 1346-1349 (2006). 
6. X. Dong, M. Dong, Y. Lu, A. Turley, T. Jin, C. Wu, Ind Crops Products 34, 1629-1634 (2011).

7. C. Pouteau, P. Dole, B. Cathala, L. Averous, N. Boquillon, Polym Degradation Stab 81, 9-18 (2003).

8. M.P. Vinnardell, V. Ugartondo, M. Mitjans, Ind Crops Products 27, 220-223 (2008). 